\title{
Factors associated with depression and suicide among patients with diabetes mellitus and essential hypertension in a Nigerian teaching hospital
}

\author{
*Igwe $\mathrm{MN}^{1}$, Uwakwe $\mathrm{R}^{2}$, Ahanotu $\mathrm{CA}^{1}$, Onyeama $\mathrm{GM}^{3}$, Bakare $\mathrm{MO}^{4}$, Ndukuba $\mathrm{AC}^{3}$
}

1. Department of Psychological Medicine, Federal Teaching Hospital Abakaliki, Ebonyi State Nigeria.

2. Department of Mental Health, Nnamdi Azikiwe University Teaching Hospital Nnewi, Anambra State Nigeria.

3. Department of Psychological Medicine, University of Nigeria Teaching Hospital Ituku-Ozalla, Enugu State Nigeria.

4. Child and Adolescent Unit, Federal Neuropsychiatric Hospital, New Haven Enugu, Enugu State Nigeria.

\begin{abstract}
Background: Diabetes mellitus (DM) and essential hypertension are chronic medical conditions that place a lot of burden on patients. The presence of depression and suicidal behaviour may worsen the prognosis.

Objective: To assess the prevalence of depression and suicidal behaviour in subjects with diabetes mellitus and essential hypertension and also determine the socio-demographic correlates.

Methods: Major depressive episode and suicidality modules of Mini-International Neuropsychiatric Interview were used to assess depression and suicidal behaviour respectively.

Results: The prevalence of depression for the subjects with DM was $27.8 \%$ and $26.7 \%$ for essential hypertension. The subjects with DM had prevalence of $6.3 \%$ for suicidal behaviour while essential hypertension had $7.8 \%$. Depression was higher in subjects with DM if they were not married or had no education while the subjects with essential hypertension were more likely to have depression if they were not married, had no education or not employed. Suicidal behaviour was higher in subjects with DM if they had no education while in essential hypertension suicidal behaviour was higher in females, those not married and those not educated.

Conclusion: Depression and suicidal behaviour occur with DM and essential hypertension.

African Health Sciences 2013; 13(1): 68 - 77 http://dx.doi.org/10.4314/ahs.v13i1.10
\end{abstract}

\section{Introduction}

Many chronic medical conditions are complicated by emotional and psychological disorders and yet the emotional dimensions of such chronic medical conditions are often overlooked when medical care is considered. ${ }^{1}$ Patients with chronic medical conditions often have to adjust their aspirations, lifestyle, and employment. Many grieve about their predicament before adjusting to it. But others have protracted distress and may develop psychiatric disorders, most commonly depression and anxiety. ${ }^{1}$ Depressive symptoms and syndromes are common in the medically ill, although they are frequently unrecognized and untreated. ${ }^{2}$ Diabetes mellitus is one

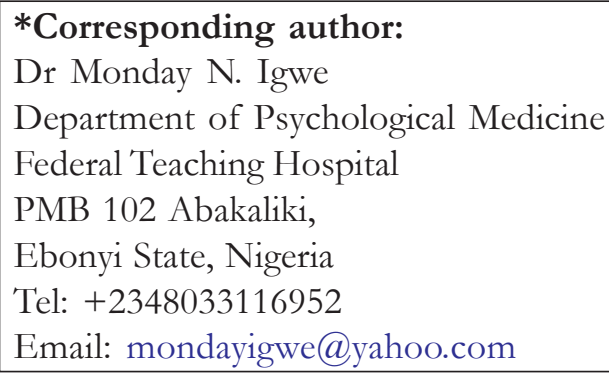

of such chronic medical conditions that could be associated with depressive syndromes.

Adaptation to chronic diseases like diabetes mellitus is a difficult and complex process. This may necessitate several adjustments in the patient's lifestyle. ${ }^{3}$ Social relationships may also be severely affected and commonly emotional responses like withdrawal, loneliness, guilt feelings, hopelessness and suicidal ideation have been noted. ${ }^{4}$ Emotional and psychological disorders may affect the quality of life of the patients and may have deleterious concomitants like suicidal ideation and behaviour. The risk of suicide has been noted to be higher among patients with physicalillnesses than the general population with a prevalence estimate of $22-60 \%{ }^{5}$,

There is a bidirectional association between depression and diabetes. The presence of diabetes doubles the odds of co-morbid depressive disorder. ${ }^{7}$ Similarly, the presence of depressive symptoms makes the afflicted individual more vulnerable to becoming diabetic. ${ }^{8}$ Indeed, patients 
who have diabetes mellitus, diagnosed with comorbid depression have an elevated risk of death from both causes, greater than that of depression or diabetes alone ${ }^{9}$. Furthermore, studies suggest that in patients with diabetes mellitus who have depression, the severity of depression is correlated with the severity of diabetes-related complications, independent of the type of diabetes. ${ }^{7}$ Depression has also been noted as a modifiable risk factor whose treatment could improve glycaemic control and health outcomes in patients with diabetes mellitus. ${ }^{10}$

A population-based mail survey study reported that independent factors that were associated with a significantly higher likelihood of meeting criteria for major depressive disorder among patients with diabetes mellitus included younger age, female sex, less education, single status, basal metabolic index $>30 \mathrm{~kg} / \mathrm{m} 2$, smoking, higher non-diabetic medical co-morbidity, higher numbers of diabetes complications in men, treatment with insulin, and higher HbA1c levels in patients $<65$ years of age. ${ }^{11}$

In another study, where 506 patients who have diabetes mellitus were assessed for depressive disorders and depressive symptoms using a structured interview (Composite International Diagnostic Interview [CIDI]), and a questionnaire for depressive symptoms (Center for Epidemiological Studies Depression Scale [CESD], it was reported that the prevalence of depressive symptoms was $22 \%$ while $9.9 \%$ met a CIDI diagnosis of major depressive disorder. ${ }^{12}$

Similarly, in a study of 60,869 participants with diabetes mellitus and healthy individuals used as control, several factors were associated with depression in types 1 and 2 diabetes. However, these factors were not different from those of the nondiabetic population. Co-morbid chronic somatic diseases were associated with depression in type 2 but not type 1 diabetes mellitus. In type 2 diabetes mellitus, those without co-morbidity had the same odds of depression as the non-diabetic population with no chronic somatic diseases. No significant associations were found for hyperglycemia in relation to depression in type 1 and type 2 diabetes mellitus. ${ }^{13}$

A research work involving 458 participants with diabetes and 546 without diabetes and used Beck Depression Inventory-II, showed that compared with non-diabetic participants, adults with type 1 diabetes reported more symptoms of depression and more antidepressant medication usage. Mean BDI-II score, adjusted for age and sex, was significantly higher in participants with type 1 diabetes than in non-diabetic participants and participants reporting diabetes complications had higher mean BDI-II scores than those without complications. ${ }^{10}$

In a meta-analysis that involved 42 studies, it was noted that the odds of depression in the group with diabetes mellitus were twice that of those without diabetes mellitus. The prevalence of comorbid depression was significantly higher in diabetic women (28\%) than in diabetic men (18\%). Prevalence of depression in the uncontrolled population was $30 \%$ while in the controlled studies it was $21 \%$. Prevalence of depression in clinical samples was $32 \%$ and in community studies was $20 \%$. Prevalence when assessed by self-report questionnaires was $31 \%$ but by standardized diagnostic interviews it was $11 \%{ }^{14}$ Association between major depression and cardiovascular disease has been established and hypertension is significantly associated with symptoms of depression. ${ }^{15}$ Among 452 psychiatric outpatients, DSM-III diagnoses of major depression were three times as common among those with hypertensive disease as those without hypertension. Age, sex, chronic medical illness, and current antihypertensive medication did not account for these diagnostic differences. ${ }^{16}$ Furthermore, mild depressive symptoms were reported in $20 \%$ of patients with hypertension. ${ }^{17}$

Also, hopelessness was associated with increased incidence of hypertension in 616 Finish men, who had normal blood pressure initially, in a 4-year followup prospective study. Participants who had high levels of hopelessness at baseline were 3 times more likely to become hypertensive than those who were not hopeless, after adjustments for age, body mass index, baseline resting blood pressure, physical activity, smoking, alcohol consumption, education, and parental history of hypertension. ${ }^{18}$

Local studies undertaken in Nigeria have reported varied results. A study that assessed the psychological condition of Nigerian subjects with diabetes mellitus reported a prevalence rate of $25 \%$ for depression ${ }^{19}$ whereas another similar study reported a prevalence of depression as $4 \%$ among attendees of a general hospital department. ${ }^{20}$ Both studies concluded that psychiatric symptomatology was associated with low occupational status, duration of diabetes and sexual dysfunction. ${ }^{19,} 20$

Another local study conducted at Ile-Ife, Nigeria among patients with diabetes mellitus, using patients with asthma and apparently healthy individuals as control, recorded the prevalence of 
depression as $20 \%$ compared to that in asthma $(12 \%)$. Predictors of depression included age of the patient, poor glycemic control and duration of diabetes mellitus. Factors that correlated significantly with diabetic general well-being include depression, anxiety and fasting blood glucose level. Depression and the presence of co-morbid medical conditions significantly predicted a low quality of life. ${ }^{4}$

Clinical depression has been documented to be a common problem among patients who have diabetes mellitus in Nigeria and those with co-morbid depression tend to have higher health care costs. ${ }^{21}$ The prevalence rate of major depressive episode was $19.4 \%$ and depression was significantly correlated with sex, with a female to male ration of $3: 1$ and was also significantly associated with unmarried patients and those who had a poor relationship with their partners. There was no significant association between depression and respondents' age, educational qualifications, employment status, place of residence, household composition and monthly income. ${ }^{21}$

Depression is not only highly co-morbid with diabetes mellitus but also affects treatment goals negatively. This study, recently conducted at the University of Benin Teaching Hospital, Nigeria reported a prevalence of clinical depression as 30\% among those who have diabetes mellitus compared with $9.5 \%$ in the apparently healthy control group. Having a smaller income and more children were significantly correlated with higher depression symptoms on Beck depression inventory. ${ }^{22}$

Recently a study examined the role of diabetes in suicide ideation and attempt, independent of mood disorders or the side effects of psychotropic drugs and found that patients with diabetes, compared to a control group, scored higher on two subscales of the Beck Hopelessness Scale: Loss of Motivation and Future Expectations, which are significantly related to suicidality. Patients with diabetes mellitus also registered higher for suicidality on the Suicide Score Scale and showed significantly lower selfefficacy than the control group.?

Adolescents with diabetes mellitus displayed higher than expected rates of suicidal ideation, but relatively few attempted suicide over the follow-up period. Among those who did attempt suicide, diabetesrelated methods commonly used were potentially lethal doses of insulin which were easily available to them. Suicidal ideation shortly after insulin dependent diabetes mellitus onset was related only to concurrent severity of depressive symptoms. Also, it has been noted that suicidal ideation and not complying with medical regimen are strongly associated among teenagers with diabetes mellitus. ${ }^{23}$

Patients with diabetes undergoing polytherapy are at a higher risk for suicide ideation and attempt. Type of diabetes mellitus is not thought to be a significant risk factor, but rather, the severity of the symptoms and the inconvenience of the treatment are thought to be more relevant. Patients with combined treatments tend to score higher on several measures in the Beck Hopelessness Scale. Patients with diabetes mellitus who are above 50 years of age are at a higher risk of suicide ideation and attempt. ${ }^{\top}$

Untreated psychiatric illness is associated with increased morbidity, a longer hospital stay and ultimately, increased costs of care. ${ }^{24}$ This often leads to wasteful, costly and inefficient use of medical services and complications of the disorders and treatments among these patients. ${ }^{25}$

Therefore, early detection and treatment of mental disorders are essential.

Awareness about co-morbidity of depression and suicidal behaviour with diabetes mellitus and essential hypertension is essential to effective and holistic management of patients with these chronic medical conditions. Therefore, this study was designed to assess the prevalence of depression and suicidal behaviour in subjects with diabetes mellitus and essential hypertension and also determined the socio-demographic correlates.

\section{Methods}

\section{Study setting}

This study was carried out at the endocrinology and cardiology clinics of University of Nigeria Teaching Hospital Enugu. The hospital began as a General Hospital for Africans at a temporary site in Ogbete area of Enugu metropolis. Presently the new site is at Ituku-ozalla and located 21 kilometers from Enugu city along the Enugu-Port Harcourt express way. The hospital site covers an area of 200 acres with the entire parcel of land measuring about 747 acres. The bed capacity is 702 with average daily bed occupancy being 500. The hospital offers 24- hour emergency service as well as outpatient clinics that include diabetic and cardiology units. The services of the Hospital are highly subsidized by the Federal Government of Nigeria. Patients from south-east, south-south and north-central geo-political zones of Nigeria receive care in this tertiary referral centre. 


\section{Ethical approval}

The ethical approval for the study was obtained from the Institutional Review Board (IRB) of University of Nigeria Teaching Hospital Ituku-ozalla, Enugu State Nigeria. Written informed consent was also obtained from the respondents that participated in the study.

\section{Participants and sampling method}

Participants were subjects diagnosed of type 1 or type 2 diabetes mellitus by a consultant endocrinologist. Subjects diagnosed to have essential hypertension by a consultant cardiologist formed the second group.

Subjects recruited were aged 18 - 64 years. They would have been diagnosed of the disease for at least 1 year and stable without need for hospital admission for 3 months prior to assessment. This was to ensure they had understood the dynamics of the disease. All these were the inclusion criteria. Subjects with co-morbid diabetes mellitus and hypertension were excluded. Subjects with past history of mental illness, head injury or substance abuse were also excluded from the study.

Two hundred and seventy consecutive subjects with diabetes mellitus who met the inclusion criteria were recruited into the study from the endocrinology clinic. Similarly 270 consecutive subjects were recruited from the cardiology clinic. Subjects who had diabetes mellitus were closely matched with those who had essential hypertension in terms of age ( \pm 5years) and sex. The study was carried out over 6 months period (between August, 2010 and January, 2011). The authors administered all the instruments to the subjects: socio-demographic questionnaire, major depressive episode and suicidality modules of Mini-International Neuropsychiatric Interview. Subjects who did not understand English language were interviewed with the translated Igbo versions of the instruments.

\section{The socio-demographic questionnaire}

This questionnaire was designed to provide information about the respondents' age, gender, marital status, occupation, level of education, ethnic background, religion, age of onset of diabetes mellitus/essential hypertension and duration of illness.

\section{The Mini-International Neuropsychiatric interview}

The Mini-International Neuropsychiatric Interview (M.I.N.I.) is a short structured diagnostic interview, developed jointly by psychiatrists and clinicians in the United States and Europe in 1990 for DSM-IV and ICD-10 psychiatric disorders. With an administration time of approximately 15 minutes, it was designed to meet the need for a short but accurate structured psychiatric interview for multicenter clinical trials and epidemiology studies and is expected to be used as a first step in outcome tracking in non-research clinical settings ${ }^{26} \mathrm{It}$ is a widely used instrument by health professionals and organizations with translations into many languages. ${ }^{27}$ It can be used by clinicians after a brief training session while lay interviewers require more extensive training. There are many modules for diagnostic categories but only the major depressive episode and suicidality modules were used. Major Depressive Episode module of MINI which is grouped as Amodule has six sections A1 to A6. In this study questions A1 to A3 were used since the study assessed major depressive episode (current).

The Suicidality module of this instrument which is grouped as C Module was used for this study. There were nine questions in this module labelled C1 to C9. Questions C1 to C8 assessed events in the past one month while question C9 assessed for suicide attempt in a patient's lifetime. This module assessed suicidal behaviour which included suicidal intent, plan and attempt. Scores were graded as low, medium and high. However those who scored low and moderate in this study were grouped together as low-moderate risk and compared with those that scored high on MINI.

\section{Data analysis}

Analysis was done with the Statistical Package for Social Sciences (SPSS version 16). Frequency counts and chi-square $\left(\mathrm{x}^{2}\right)$ test were used for categorical variables while continuous variables were analyzed using the student t-test. All statistical values were set at $5 \%$ level of significance $(p<0.05)$.

\section{Results}

\section{Socio-demographic variables}

There were 540 subjects that participated in the study, 270 each for diabetes mellitus and essential hypertension respectively. In each group, 125 (46.3\%) were females and $145(53.7 \%)$ were males $\left(\mathrm{X}^{2}=\right.$ $0.00, \mathrm{p}=1.00)$ The mean age for the subjects with diabetes mellitus was $51.0 \pm 10.1$ years and this did not significantly differ from $50.4 \pm 9.4$ years for the subjects with essential hypertension $(t=0.73, p=$ 0.47). Amongst the subjects with diabetes mellitus, 
$210(77.8 \%)$ were married while for the subjects with essential hypertension, $216(80 \%)$ were married $\left(\mathrm{X}^{2}\right.$ $=0.40, \mathrm{p}=0.53)$. Twenty four $(8.9 \%)$ of the subjects with diabetes mellitus had no formal education while among the group with essential hypertension, forty seven $(17.4 \%)$ had no formal education $\left(X^{2}=8.58\right.$, $\mathrm{p}=0.06)$. Table 1 shows the socio-demographic variables of the subjects.

Table 1: Socio-demographic characteristics of the subjects

\begin{tabular}{|c|c|c|c|}
\hline Variables & DM & HTN & Statistics \\
\hline Sex & $\underline{\mathrm{n}(\%)}$ & n (\%) & \\
\hline Female & $125(46.3)$ & $125(46.3)$ & $\mathrm{X}^{2}=0.00$ \\
\hline Male & $145(53.7)$ & $145(53.7)$ & $p=1.00$ \\
\hline \multicolumn{4}{|l|}{ Age (years) } \\
\hline $20-29$ & $12(4.4)$ & $9(3.3)$ & \\
\hline $30-39$ & $15(5.6)$ & $27(10.0)$ & \\
\hline $40-49$ & $69(25.6)$ & $75(27.8)$ & \\
\hline $50-59$ & $102(37.8)$ & $99(36.7)$ & \\
\hline $60-64$ & $72(26.7)$ & $60(22.2)$ & $t=0.73$ \\
\hline Mean + SD & $51.04 \pm 10.07$ & $50.43 \pm 9.43$ & $\mathrm{p}=0.47$ \\
\hline \multicolumn{4}{|l|}{ Marital status } \\
\hline Married & $210(77.8)$ & $216(80.0)$ & $X^{2}=0.40$ \\
\hline Not married & $60(22.2)$ & $54(20.0)$ & $\mathrm{p}=0.53$ \\
\hline \multicolumn{4}{|l|}{ Religion } \\
\hline Christianity & $258(95.6)$ & $258(95.6)$ & $\mathrm{X}^{2}=0.00$ \\
\hline ATR & $12(4.4)$ & $12(4.4)$ & $\mathrm{p}=1.00$ \\
\hline \multicolumn{4}{|l|}{ Ethnic group } \\
\hline Igbo & $264(97.8)$ & $267(98.9)$ & $X^{2}=1.52$ \\
\hline Others & $6(2.2)$ & $3(1.1)$ & $\mathrm{p}=0.47$ \\
\hline \multicolumn{4}{|c|}{ Education attainment } \\
\hline $\begin{array}{l}\text { No formal } \\
\text { education }\end{array}$ & $24(8.9)$ & $47(17.4)$ & $\mathrm{X}^{2}=8.58$ \\
\hline Formal education & $246(91.1)$ & $223(82.6)$ & $p=0.06$ \\
\hline \multicolumn{4}{|c|}{ Employment status } \\
\hline Employed & $186(68.9)$ & $217(80.4)$ & $\mathrm{X}^{2}=9.40$ \\
\hline Not employed & $84(31.1)$ & $53(19.6)$ & $\mathrm{p}<0.001$ \\
\hline
\end{tabular}

Rates of depression (current episode) and suicidal behaviour among the subjects with diabetes mellitus and essential hypertension

On the M.I.N.I, the rate of depression among the subjects with diabetes mellitus was $27.8 \%$ while the subjects with essential hypertension had $26.7 \%\left(\mathrm{X}^{2}\right.$ $=0.08, \mathrm{p}=0.77)$. Subjects with essential hypertension who exhibited suicidal behaviour were $21(7.8 \%)$ whereas 17 (6.3\%) of the subjects with DM exhibited suicidal behaviour $\left(\mathrm{X}^{2}=0.45, \mathrm{p}=0.50\right)$. However, the subjects with diabetes mellitus scored higher on the suicidality module of M.I.N.I. compared to the subjects with essential hypertension. Twenty one $(7.8 \%)$ of the subjects with essential hypertension scored low - moderate compared to $14(5.2 \%)$ of the subjects with diabetes. Three $(1.1 \%)$ of the subjects with diabetes mellitus scored high while none $(0 \%)$ of the subjects with essential hypertension scored high on suicidality module of M.I.N.I. $\left(\mathrm{X}^{2}=\right.$ $7.5, \mathrm{p}=0.06$ ). Table 2 shows the rates of depression (current episode) and suicidal behaviour/risk among the subjects with DM and essential hypertension. 
Table 2: Depression (current episode) and suicidal behaviour among the subjects with DM and essential hypertension

\begin{tabular}{|c|c|c|c|}
\hline & DM & HTN & Statistics \\
\hline \multirow[t]{2}{*}{ Depression } & $\mathrm{n}(\%)$ & n $(\%)$ & \\
\hline & 75 (27.8) & $72(26.7)$ & $\mathrm{X}^{2}=0.08, \mathrm{p}=0.77$ \\
\hline \multicolumn{4}{|c|}{ Suicidal behaviour } \\
\hline Yes & $17(6.3)$ & $21(7.8)$ & $\mathrm{X}^{2}=0.45$ \\
\hline No & $253(93.7)$ & 249 (92.2) & $\mathrm{p}=0.50$ \\
\hline \multicolumn{4}{|l|}{ Suicidal risk } \\
\hline $\begin{array}{l}\text { Low - moderate } \\
\text { High }\end{array}$ & $\begin{array}{l}14(5.2) \\
3(1.1)\end{array}$ & $\begin{array}{c}21(7.8) \\
0(0)\end{array}$ & $\begin{array}{l}X^{2}=7.5 \\
p=0.06\end{array}$ \\
\hline
\end{tabular}

Association between depression and sociodemographic variables

Two hundred and ten subjects with diabetes mellitus were married and $48(22.9 \%)$ of them had depression. The non-married subjects were more likely to have depression than those who were married $\left(\mathrm{X}^{2}=11.41, \mathrm{p}<0.001\right)$. Fifty four subjects with essential hypertension were not married (single, widowed, divorced or separated) and 24 (44.4\%) of them had depression. Significantly more nonmarried subjects were likely to have depression compared to those who were married among the subjects with essential hypertension $\left(\mathrm{X}^{2}=10.91, \mathrm{p}<\right.$ 0.001). Table 3 shows the distribution of depression according to marital status among the subjects with diabetes mellitus and essential hypertension

Table 3: Distribution of depression according to marital status among the subjects with diabetes mellitus and essential hypertension

\begin{tabular}{|c|c|c|c|}
\hline Marital status & $\mathrm{n}$ & Yes & $\begin{array}{l}\text { Percent } \\
(\%)\end{array}$ \\
\hline \multicolumn{4}{|l|}{ DM } \\
\hline Married & 210 & 48 & $22.9 \mathrm{X}^{2}=11.41$ \\
\hline Not married & 60 & 27 & $45 \quad \mathrm{p}<0.001$ \\
\hline \multicolumn{4}{|l|}{ HTN } \\
\hline Married & 216 & 48 & $22.2 \mathrm{X}^{2}=10.91$ \\
\hline Not married & 54 & 24 & $44.4 \mathrm{p}<0.001$ \\
\hline
\end{tabular}

Association between depression and educational status among the subjects with diabetes mellitus and essential hypertension

Twenty four patients with diabetes mellitus had no formal education and $13(54.2 \%)$ of them had depression. The subjects with no formal education were more likely to have depression compared to those with formal education $\left(\mathrm{X}^{2}=14.51, \mathrm{p}<0.001\right)$. Depression was higher among the subjects with essential hypertension without formal education compared to those with formal education $\left(\mathrm{X}^{2}=\right.$
17.32, $\mathrm{p}<0.001)$. Table 4 shows the distribution of depression according to educational status among the subjects with diabetes mellitus and essential hypertension.

Table 4: Distribution of depression according to educational status among the subjects with diabetes mellitus and essential hypertension

\begin{tabular}{|c|c|c|}
\hline Educational status & $\mathbf{n}$ & $\begin{array}{cl}\text { Yes } & \begin{array}{c}\text { Percent } \\
(\%)\end{array}\end{array}$ \\
\hline \multicolumn{3}{|l|}{$\overline{\mathbf{D M}}$} \\
\hline No formal education & 24 & $1354.2 \mathrm{X}^{2}=14.51$ \\
\hline Formal education & 246 & $6928 \mathrm{p}<0.001$ \\
\hline \multicolumn{3}{|l|}{ HTN } \\
\hline No formal education & 47 & $2451.1 \mathrm{X}^{2}=17.32$ \\
\hline Formal education & 223 & $4821.5 \mathrm{p}<0.001$ \\
\hline
\end{tabular}

Association between depression and employment status among the subjects with diabetes mellitus and essential hypertension One hundred and eighty six of the subjects with diabetes mellitus were employed and $45(24.2 \%)$ had depression. Eighty four patients were not employed, $30(35.7 \%)$ of whom had depression. Two hundred and seventeen of the subjects with essential hypertension were employed and 51 (23.5\%) of them had depression. Depression was more likely in patients with no jobs $\left(X^{2}=5.67, p=0.02\right)$. Table 5 shows the distribution of depression according to employment status among the subjects with diabetes mellitus and essential hypertension. 
Table 5: Distribution of depression according to employment status among the subjects with diabetes mellitus and essential hypertension

\begin{tabular}{|c|c|c|c|c|}
\hline $\begin{array}{l}\text { Employment } \\
\text { status }\end{array}$ & n & Yes & $\begin{array}{l}\text { Percent } \\
(\%)\end{array}$ & \\
\hline \multicolumn{5}{|l|}{$\mathbf{D M}$} \\
\hline Employed & 186 & 45 & 24.2 & \\
\hline $\begin{array}{l}\text { Unemployed } \\
\text { HTN }\end{array}$ & 84 & 30 & 35.7 & \\
\hline Employed & 217 & 51 & 23.5 & $X^{2}=5.67$ \\
\hline Not employed & 53 & 21 & 39.6 & $p=0.02$ \\
\hline
\end{tabular}

Association between suicidal behaviour (suicidal ideation, plan and attempt) and sociodemographic variables

Association between suicidal behaviour and gender among the subjects with diabetes mellitus and essential hypertension

Eight female subjects with DM (6.4\%) had suicidal behaviour compared to $9(6.2 \%)$ male subjects with suicidal behaviour $\left(\mathrm{X}^{2}=0.00, \mathrm{p}=0.95\right)$. Female subjects with essential hypertension were more likely to have suicidal behaviour $\left(\mathrm{X}^{2}=5.79, \mathrm{p}=0.02\right)$. Table 6 shows the distribution of suicidal behaviour according to gender among the subjects with diabetes mellitus and essential hypertension.

Table 6: Association between suicidal behaviour and gender among the subjects with diabetes mellitus and essential hypertension

\begin{tabular}{lllll}
\hline Gender & n & Yes & $\begin{array}{l}\text { Percent } \\
\mathbf{( \% )}\end{array}$ \\
\hline DM & & & & \\
Female & 125 & 8 & 6.4 & $\mathrm{X}^{2}=0.00$ \\
Male & 145 & 9 & 6.2 & $\mathrm{p}=0.95$ \\
HTN & & & & \\
Female & 125 & 15 & 12 & $\mathrm{X}^{2}=5.79$ \\
Male & 145 & 6 & 4.1 & $\mathrm{p}=0.02$ \\
\hline
\end{tabular}

Association between suicidal behaviour and marital status among the subjects with diabetes mellitus and essential hypertension

Five $(8.3 \%)$ of the subjects with diabetes mellitus who were single (never married, widowed, divorced or separated), exhibited suicidal ideation, plans or attempts compared to $12(5.7 \%)$ married subjects who had suicidal behaviour. However, subjects with essential hypertension who were single (never married, widowed, separated or divorced) were more likely to have suicidal ideation, plans or attempt $\left(\mathrm{X}^{2}=19.63, \mathrm{p}<0.001\right)$. Table 7 shows the distribution of suicidal behaviour according to marital status among the subjects with diabetes mellitus and essential hypertension.

Table 7: Distribution of suicidal behaviour according to marital status among the subjects with diabetes mellitus

\begin{tabular}{lllll}
\hline $\begin{array}{l}\text { Marital status } \\
\text { DM }\end{array}$ & n & Yes & Percent $\mathbf{( \% )}$ \\
\hline Married & 210 & 12 & 5.7 & \\
Not married & 60 & 5 & 8.3 & \\
HTN & & & & \\
Married & 216 & 9 & 4.2 & $\mathrm{X}^{2}=19.63$ \\
Not Married & 54 & 12 & 22.2 & $\mathrm{p}<0.001$ \\
\hline
\end{tabular}

Association between suicidal behaviour and educational status among the subjects with diabetes mellitus and essential hypertension Subjects with diabetes mellitus having no formal education were more likely to exhibit suicidal ideation, plans and attempts. Twenty four subjects with diabetes mellitus had no formal education and $5(20.8 \%)$ of them had suicidal behaviour compared to $12(4.9 \%)$ who had formal education and also had suicidal behaviour $\left(\mathrm{X}^{2}=9.44, \mathrm{p}<0.001\right)$. Subjects with essential hypertension who had no formal education were more likely to exhibit suicidal behaviour compared to the subjects who had formal education. Nine $(19.1 \%)$ of the subjects who had no formal education had suicidal behaviour while $12(5.4 \%)$ of the subjects who had formal education (primary, secondary or tertiary) had suicidal behaviour $\left(\mathrm{X}^{2}=10.26, \mathrm{p}<0.001\right)$. Table 8 shows the distribution of suicidal behaviour according to educational status among the subjects with diabetes mellitus and essential hypertension.

Table 8: Distribution of suicidal behaviour according to educational status among the subjects with diabetes mellitus and essential hypertension

\begin{tabular}{llll}
\hline Educational status & $\mathbf{N}$ & \multicolumn{2}{l}{ Yes Percent $\mathbf{~ ( \% )}$} \\
\hline No education & 24 & 5 & $20.8 \mathrm{X}^{2}=9.44$ \\
Formal education & 246 & 12 & $4.9 \mathrm{p}<0.001$ \\
HTN & & & \\
No education & 47 & 9 & $19.1 \mathrm{X}^{2}=10.26$ \\
Formal education & 223 & 12 & $5.4 \mathrm{p}<0.001$ \\
\hline
\end{tabular}




\section{Discussion}

\section{Rates of depression (current episode)}

The depression rate using Mini-International Neuropsychiatric Interview (M.I.N.I.) was $27.8 \%$ for the subjects with diabetes mellitus and $26.7 \%$ for the subjects with essential hypertension $(p=0.77)$. The finding was close to an earlier hospital based study conducted at a teaching hospital in Benin, Nigeria among patients with diabetes mellitus. The study employed similar methodology with the present study and reported a 30\% prevalence of clinical depression among the subjects with diabetes mellitus using the depression module of the Schedule for the Clinical Assessment in Neuropsychiatry. ${ }^{22}$

Furthermore, the prevalence of depression among the subjects with diabetes mellitus was $27.8 \%$ and this was close to the $25 \%$ reported in another study among a cohort of Nigerians with diabetes mellitus ${ }^{19}$ but higher than the $20 \%$ reported in another study among subjects with diabetes mellitus. ${ }^{4}$

The finding of prevalence of $26.7 \%$ of depression among the subjects with essential hypertension was higher compared to a previously reported $20 \%$ in a study that assessed depressive symptoms and association with unhealthy lifestyles in subjects with hypertension. ${ }^{17}$

\section{Suicidal behaviour (ideation, plan and attempt)} The findings from this study showed that proportionally, subjects with essential hypertension exhibited suicidal ideation, plan and attempt (7.8\%), compared to the subjects with diabetes mellitus $(6.3 \%)$. However, suicidal risk was higher in patients with diabetes mellitus. Three $(1.1 \%)$ subjects with diabetes mellitus scored high on the suicidality module of M.I.N.I. These findings were in agreement with a previous Italian study of quality of life and suicidal risk in subjects with diabetes mellitus. The authors reported that subjects with diabetes mellitus showed greater hopelessness and suicidal ideation $(7.4 \%)$ than internal medicine outpatients $(6.5 \%) .^{7}$

The present finding is however in contrast to that reported in a US study. The authors examined the association between the presence of a general medical illness and suicidality in a representative sample of US young adults and reported that $25.2 \%$ of those with a general medical illness had suicidal ideation and $8.9 \%$ had made suicide attempts at a point in their lives. ${ }^{28}$ The reason for the lower figures in the present study may be that suicidal behaviour is intolerable in Igbo society even in this modern time. Suicide is considered an offence against the Earth and anyone who commits suicide brings shame to the family, village and the town. ${ }^{29}$ This cultural norm may discourage suicidal behaviour or encourage subjects to conceal them.

\section{Correlates of depression}

This study found a significant association between not being married and having no formal education and having diagnosis of depression among patients with diabetes mellitus. Depression was more likely in patients with essential hypertension if the subjects were not married, not educated and not employed. Marriage offers caregiving and social supports to subjects with diabetes mellitus or essential hypertension. It has been shown that the family is a major source of support for psychological adjustments of patients to disease. ${ }^{30}$ Such may not be available to subjects who were single, divorced or widowed.

Having no formal education was associated with depression in this study. Lack of education is a strong impediment to understanding the dynamics of chronic medical conditions and complexities involved in good glycaemic control for the subjects with diabetes mellitus. This finding was in agreement with a previous study that reported less number of years of formal education as significantly associated with depression among subjects with diabetes. ${ }^{31}$

By extrapolation, subjects with less education or no formal education may earn less as they are likely to get poorly paid jobs. Subjects with low earning power face the burden of maintaining life style changes that could sustain cost of medication adherence and dietary restrictions necessary for good glycaemic control in diabetes mellitus. The relationship between earning power and depression in diabetes mellitus has been reported in a similar cross-sectional study of 200 subjects with diabetes mellitus at the University of Benin Teaching Hospital, Nigeria. The authors used the depression module of Schedule for the Clinical Assessment in Neuropsychiatry (SCAN) to diagnose depression and Beck Depression Inventory to assess depression and its severity. ${ }^{22}$

Although female subjects and those not employed with diabetes mellitus were more likely to have depression, this study found no statistically significant associations. This agreed with another study which reported no significant associations between female gender and depression among subjects with diabetes. ${ }^{22}$ However, this contrasts with a report of another study that found significant 
associations between female and depression among the subjects with diabetes mellitus. ${ }^{31}$

\section{Correlates of suicidal behaviour}

Suicidal behaviour (ideation, plan and attempt) was likely in subjects with diabetes mellitus if they had no formal education while in patients with essential hypertension suicidal behaviour was likely in females, those not married and those not educated. Diabetes mellitus may have profound effects on physical health, emotional health and quality of life. ${ }^{7}$ Having no formal education may predispose to low selfesteem and lead to feelings of hopelessness as the patient battles with understanding the dynamics of the disease. Presence of the disease in a subject with no education is therefore a double burden.

\section{Limitations of the study}

This study was a cross-sectional based nonpopulation representative study. Its results cannot be generalized to the entire population. No causal links or directions can be inferred in a cross-sectional survey of this nature. Socio-demographic variables of educational attainment and employment status were not closely matched among the two groups. Despite these caveats, the findings from this study should serve as a baseline data for comparison in future studies especially in South-eastern Nigeria.

\section{Conclusion}

The findings of this study showed that depression and suicidal behaviour may co-occur with diabetes mellitus and essential hypertension.

\section{References}

1. Turner J, Kelly B. Emotional dimensions of chronic disease. West J Med 2000; 17(2): 124128.

2. Rodin G, Voshart K. Depression in the medically ill: an overview. Am J Psychiatry 1986; 143: 696-705.

3. Brannon L, Feist J. Living with chronic illness, in Health Psychology: An Introduction to Behavior and Health. Pacific Grove, Calif, Brooks/Cole. 1997; 265-300.

4. Mosaku K, Kolawole B, Mume C, Ikem R. Depression, Anxiety and Quality of Life among Diabetic Patients: A Comparative Study. Journal of the National Medical Association 2008; $100(1)$ : 73-78.

5. Kishi Y, Robinson RG, Kosier JT. Suicidal ideation among patients with acute life - threatening physical illness. Psychosomatics 2001; 42: 382-390.

6. Shah A, Hoxey A, Mayadunne V. Suicidal ideation in acutely medically ill elderly inpatients: prevalence, correlates and longitudinal stability. International Journal of Geriatric Psychiatry 2000; 15(2): 162-169.

7. Pompili M, Lester D, Innamorati M, DePisa E, Amore M, Ferrara C, Tatarelli R, Girardi P. Quality of life and suicide risk in patients with diabetes mellitus. Psychosomatics 2009; 50(1): 1623.

8. Brownlee C. Depression and Diabetes Are Fellow Travelers, Researchers Say. The JHU Gazette 2008; 37(40): 1-2.

9. Egede L, Nietert P, Zheng D. Depression and All-Cause and Coronary Heart Disease Mortality among Adults With and Without Diabetes. Diabetes Care 2005; 28(6): 1339-1345.

10. Gendelman N, Snell-Bergeon JK, McFann K, Kinney G, Wadwa RP, Bishop F, Rewers M. Prevalence and correlates of depression in individuals with and without type 1 diabetes. Diabetes Care 2009; 32 (4) 575-579.

11. Katon W, Von Korff M., Ciechanowski P., Russo J., Lin E., Simon G., Ludman E., Walker E., Bush T, Young B. Behavioral and clinical factors associated with depression among individuals with diabetes. Diabetes Care 2004; 27 : 914-920.

12. Fisher L, Skaff MM, Mullan JT, Arean P, Mohr D, Masharani U. et al. Clinical depression versus distress among patients with type 2 diabetes; not just a question of semantics. Diabetes Care 2007; 30: 542-548.

13. Engum A, Mykletun A, Midthjell K, Holen A, Dahl AA. Depression and Diabetes; A large population-based study of socio-demographic, lifestyle, and clinical factors associated with depression in type 1 and type 2 diabetes. Diabetes Care 2005; 28(8): 1904-1909.

14. Anderson RJ, Freedland KE, Clouse RE, Lustman P. The prevalence of comorbid depression in adults with diabetes: a metaanalysis. Diabetes Care 2001; 24: 1069-1078.

15. Scherrer JF., Xian H., Bucholz KK., Eisen SA., Lyons MJ., Goldberg J. et al. A twin study of depression symptoms, hypertension, and heart disease in middle-aged men. Psychosom Med. 2003; 65(4): 548-57 
16. Rabkin J, Charles E, Kass F. Hypertension and DSM-III depression in psychiatric outpatients. Am J Psychiatry 1983; 140(8): 1072-1074.

17. Bonnet F, Irving K, Terra JL, Nony P, Berthezene F, Moulin P. Depressive symptoms are associated with unhealthy lifestyles in hypertensive patients with the metabolic syndrome. J Hypertens. 2005; 23: 611-617.

18. Everson AS, Kaplan GA, Goldberg DE, Salomen JT. Hypertension Incidence Is Predicted by High Levels of Hopelessness in Finish Men. Hypertension 2000; 34(2): 561-567.

19. Akinlade KS., Ohaeri JU., Suberu MA. The psychological condition of a cohort of Nigerian diabetic subjects. Afr J Med Med Sci.1996; 25(1): 61-67.

20. Coker AO, Ohaeri JU, Lawal RA, Orija OB Specific psychiatric morbidity among diabetics at a Nigerian General Hospital. East Afr Med J. 2000; 77(1): 42-45.

21. Agbir TM., Audu MD., Adebowale TO., Goar SG. Depression among medical outpatients with diabetes: A cross-sectional study at Jos University Teaching Hospital, Jos, Nigeria. Ann Afr Med. 2010; 9: 5-10.

22. James BO, Omoaregba JO, Eze G, Morakinyo O. Depression among patients with diabetes mellitus in Nigerian Teaching Hospital. South African Journal of Psychiatry 2010; 16:2.

23. Goldston DB, Kovacs M, Ho VY, Parrone PL, Stiffler L. Suicidal ideation and suicide attempts among youth with insulin-dependent diabetes mellitus. Journal of the American Academy of Child and Adolescent Psychiatry 1994; 33(2): 240-246.
24. Gomez J. Liaison psychiatry: mental health problems in the general hospital. Croom and Helm Publications. Beckenham, UK 1987.

25. Musisi S, Tugumisirize J. Psychiatric consultation liaison at Mulago Hospital. Makerere Univ Med School J. 2001; 35: 4-11.

26. Sheehan DV, Lecrubier Y, Sheehan KH, Amorim P, Janavs J, Weiller E. et al. The MiniInternational Neuropsychiatric Interview (M.I.N.I.): the development and validation of a structured diagnostic psychiatric interview for DSM-IV and ICD-10. J Clin Psychiatry 1998; 59 Suppl 20: 22-33.

27. Otsubo T, Tanaka K, Koda R, Shinoda J, Sano N, Tanaka S. et al. Reliability and validity of Japanese version of the Mini-International Neuropsychiatric Interview. Psychiatry Clin Neurosci 2005; 59 (5): 517-26.

28. Druss B, Pincus H. Suicidal ideation and suicide attempts in general medical illnesses. Arch Intern Med 2000; 160:1522 - 1526.

29. Ukwu D.C, Ikebudu A.I. Igbo People (Nigeria) \& Their Beliefs or Views About Suicide. Long Beach City College. 2. http:// lib.lbcc.edu/chiamaka/IgbosSuicide.

30. Bloom J, Spiegel D. The effects of two dimensions of social support in the psychological well-being and social functioning of women with advanced breast cancer. Soc Sci Med 1984; 19:831-837.

31. Mier N, Bocanegra-Alonso A, Zhan D, Wang S, Stoltz SM, Acosta-Gonzalez RI, et al. Clinical depressive symtptoms and diabetes in a Binational border population. J Am Baord Fam Med 2008; 21(3):223-233 